\title{
ON BOUNDS FOR THE SMALLEST AND THE LARGEST EIGENVALUES OF GCD AND LCM MATRICES
}

\author{
ERCAN ALTINIŞIK AND ŞERIFE BÜYÜKKÖSE
}

Abstract. In this paper, improving a famous result of Wolkowicz and Styan for the GCD matrix $\left(S_{n}\right)$ and the LCM matrix $\left[S_{n}\right]$ defined on $S_{n}=\{1,2, \ldots, n\}$, we present new upper and lower bounds for the smallest and the largest eigenvalues of $\left(S_{n}\right)$ and $\left[S_{n}\right]$ in terms of particular arithmetical functions.

Mathematics subject classification (2010): 05C88, 05C89.

Keywords and phrases: gcd matrix, lcm matrix, Euler's phi-function, eigenvalue inequalities, trace, Cauchy's interlacing theorem, Rayleigh-Ritz theorem.

\section{REFERENCES}

[1] M. Anadelić, E. Andrade, D. M. Cardoso, C. M. Da Fonseca, S. K. Simić and D. V. ToŠIĆ, Some new considerations about double nested graphs, Linear Algebra Appl., 483, (2015), 323-341.

[2] E. AltinişıK, B. E. SAGAn And N. TuG̃LU, GCD matrices, posets, and nonintersecting paths, Linear and Multilinear Algebra, 53(2), (2015), 75-84.

[3] E. ALtinişIK, On inverses of GCD matrices associated with multiplicative functions and a proof of the Hong-Loewy conjecture, Linear Algebra Appl., 430, (2009), 1313-1327.

[4] E. ALTINIŞIK AND Ş. BÜYÜKKÖSE, A proof of a conjecture on monotonic behavior of the smallest and the largest eigenvalue of a number-theoretic matrix, Linear Algebra Appl., 471, (2015), 141-149.

[5] S. Beslin And S. Ligh, Greatest common divisor matrices, Linear Algebra Appl., 118, (1989), $69-76$.

[6] O. Bordellè S, Mean values of generalized gcd-sum and lcm-sum functions, J. Integer Seq., 10, (2007), Article 07.9.2, 13 pp.

[7] O. BORDELLÈs, The composition of gcd and certain arithmetic function, J. Integer Seq., 13, (2010), Article 10.7.1, $22 \mathrm{pp}$.

[8] K. Bourque AND S. Ligh, On GCD and LCM matrices, Linear Algebra Appl., 174, (1992), 65-74.

[9] E. Ces Áro, Étude moyenne du plus grand commun diviseur de deux nombres, Ann. Mat. Pura Appl., 13, (1885), 235-250.

[10] P. HaukKanen, J. Wang And J. Sillanpë̈̈, On Smith's determinant, Linear Algebra Appl., 258, (1997), 251-269.

[11] S. Hong, Asymptotic behavior of largest eigenvalue of matrices associated with completely even functions (mod $r$ ), Asian-Europ.J. Math., 1, (2008), 225-235.

[12] S. Hong AND K. S. ENOCH LEE, Asymptotic behavior of eigenvalues of reciprocal power LCM matrices, Glasg. Math. J., 50, (2008), 163-174.

[13] S. Hong AND R. LOEWY, Asymptotic behavior of eigenvalues of greatest common divisor matrices, Glasg. Math. J., 46, (2004), 303-308.

[14] S. Hong AND R. LOEWY, Asymptotic behavior of the smallest eigenvalue of matrices associated with completely even functions ( $m o d r$ ), Int. J. Number Theory, 7, (2011), 1681-1704.

[15] R. Horn, C. R. Johnson, Matrix Analysis, Cambridge University Press, 2nd printing, London, 1985.

[16] T. HUANG AND L. WANG, Improving bounds for eigenvalues of complex matrices using traces, Linear Algebra Appl., 426, (2007), 841-854. 
[17] P. Ilmonen, P. HaukKanen and J. K. Merikoski, On eigenvalues of meet and join matrices associated with incidence functions, Linear Algebra Appl., 429, (2008), 859-874.

[18] C. R. JOHNSON, R. KUMAR AND H. WOLKOWICZ, Lower bounds for the spread of a matrix, Linear Algebra Appl., 71, (1985), 161-173.

[19] D. S. Kalogerias AND A. P. Petropulu, Matrix completion in colocated mimo radar: Recoverability, bounds and theoretical guarantees, IEEE Trans. Signal Process., 62, (2014), 309-321.

[20] I. KorkeE AND P. HAUKKANEN, On meet and join matrices associated with incidence functions, Linear Algebra Appl., 372, (2003), 127-153.

[21] P. Lindqvist AND K. Seip, Note on some greatest common divisor matrices, Acta Arith., 84.2, (1998), 149-154.

[22] M. MatTiLA, On the eigenvalues of combined meet and join matrices, Linear Algebra Appl., 466, (2015), 1-20.

[23] M. Mattila AND P. HAUKKANEN, On the eigenvalues of certain number-theoretic matrices, International Conference in Number Theory and Applications, 2012.

[24] M. Mattila AND P. HaukKanen, On the eigenvalues of certain number-theoretic matrices, EastWest J. Math., 14, (2012), 121-130.

[25] M. Mattila And P. HaukKanen, On the positive definiteness and eigenvalues of meet and join matrices, Discrete Math., 326, (2014), 9-19.

[26] J. K. MERikoski, H. SARRia AND P. TARAZAGA, Bounds for singular values using traces, Linear Algebra Appl., 210, (1994), 227-54.

[27] J. K. Merikoski, G. P. H. Styan And H. Wolkowicz, Bounds for ratios of eigenvalues using traces, Linear Algebra Appl., 55, (1983), 105-24.

[28] J. K. Merikoski and A. Virtanen, Bounds for eigenvalues using the trace and determinant, Linear Algebra Appl., 264, (1997), 101-108.

[29] J. K. MERIKOSKI AND A. VIRTANEN, The best possible lower bound for the Perron root using traces, Linear Algebra Appl., 388, (2004), 301-313.

[30] J. SÁNDOR AND B. CRSTICI, Handbook of Number Theory vol.II, Springer Verlag, 1st printing, New York, 2005.

[31] R. Sivaramakrishnan, Classical Theory of Arithmetic Functions, Marcel Deccer, 1st printing, New York, 1989.

[32] H. J. S. Smith, On the value of a certain artihmetical determinant, Proc. London Math. Soc. Ser.1, 7, (1876), 208-212.

[33] L. WANG, M-Z. XU AND T. HuAng, Some lower bounds for the spectral radius of matrices using traces, Linear Algebra Appl., 432, (2010), 1007-1016.

[34] A. Wintner, Diophantine approximations and Hilbert's space, Amer. J. Math., 66, (1944), 564-578.

[35] H. Wolkowicz ANd G. P. H. STYAN, Bounds for eigenvalues using traces, Linear Algebra Appl., 29, (1980), 471-506.

[36] J. WU AND D. WANG, Sharpening of the inequalities of Schur, Eberlein, Kress and Huang, and new location of eigenvalues, J Math. Inequal., 8, (2014), 525-535. 